\title{
CHEMICAL PROCESSES IN DEFORMATION AT LOW METAMORPHIC GRADES: Pressure Solution and Hydraulic Fracturing
}

\author{
by Alastair Beach
}

\begin{abstract}
Pressure solution has long been recognized as an important mechanism of deformation, particularly in sedimentary rocks at low metamorphic grade. Geologists have tended to study only the most easily managed aspect of pressure solution structures - their geometry as a record of rock deformation. At the same time, the most common pressure solution structures, such as stylolites in limestones, clearly evolve through complex chemical processes, as do cleavage stripes and associated syntectonic veins which are abundant in terrigenous sedimentary rocks that have been deformed under low grade metamorphic conditions. This review focusses on stripes and veins, drawing together those concepts that need integrated study in order to reach a better understanding of pressure solution.
\end{abstract}

\section{Geological Setting}

Spaced cleavage stripes are the widespread result of deformation of sandy sequences. The striping is much better developed in immature sedimentary rocks such as greywackes (Figure 1), and has a common genetic relationship (Figure 2) to the development of syntectonic veins (Beach, 1977). Thus a first approach involves examination of the mineral constituents of stripes and the intervening lithons in conjunction with any related veins, and the simple observation that stripes contain more phyllosilicates than the lithons is most important.

The geological conditions for the development of these structures have been defined through oxygen isotope and fluid inclusion studies. The dominant mechanism of deformation below about $400^{\circ} \mathrm{C}$ is pressure solution, involving dissolution of mineral grains at points of high stress (Figures 3 and 4), disfusion through the grain boundary fluid phase, and precipitation of new minerals at points of low stress. Syntectonic veins commonly accommodate the excess material removed from stripes during deformation, as shown by field relations, and confirmed by oxygen isotope studies on both veins and the adjacent rock.

\section{Mineralogical Evidence}

Traditionally, the higher percentage of phyllosilicates in the cleavage stripes has been interpreted as the result of inert accumulation through removal of more soluble material, usually quartz (Figure 5). Careful modal analyses demonstrate however that there may be a more fundamental change in mineralogy during stripe development. For example, Beach (1974) shows that in a deformed greywacke the amount of feldspar and epidote decreased into a zone of increased cleavage striping and the amount of illite-muscovite and siderite gradually increased (Figures 6 and 7). Significantly, the amount of quartz first decreased, then increased again. Such data can be rationalized into formal chemical reactions inferred to have occurred during stripe development (e.g. Beach and King, 1978; Beach, 1979).

\section{Chemical Evidence}

A quantitative assessment of the source-sink relation of stripes and veins was presented by Beach (1974); Stephens and others (1979) present detailed chemical analyses of stripes and lithons. They define losses of $\mathrm{Na}, \mathrm{Si}, \mathrm{Al}, \mathrm{Mn}, \mathrm{Fe}, \mathrm{Mg}$, and $\mathrm{Ca}$ from the stripes, measured relative to the composition of the lithons and assuming that $\mathrm{Ti}$ was immobile.

The advent of the transmission electron microscope has permitted the identification of stripes and lithons on a much smaller scale in slates and the definition of chemical and mineralogical changes associated with cleavage development (Knipe, 1982). For example, it is suggested that chemical changes were concentrated in the stripes, with the intervening areas retaining their diagenetic chemical fingerprint.

Very few data are however available on chemical changes associated with fracturing. Fracture growth is often promoted by the presence of fluids in the crack; chemical bonds

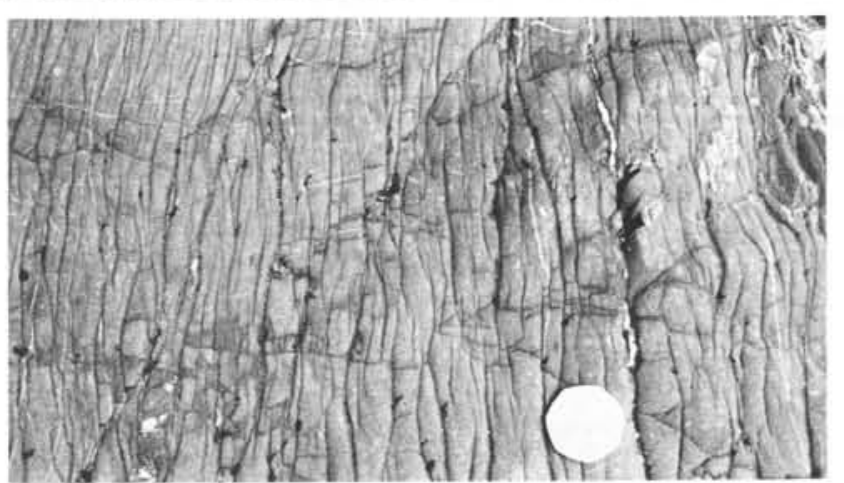

Figure 1: Pressure solution stripes in a deformed greywacke from North Devon. The stripes are seen to be anastomosing in this cross-section of bedding, and fanning slightly across a fold hinge zone. The stripes appear darker because of the increased amount of clay mineral compared with the grevwacke.

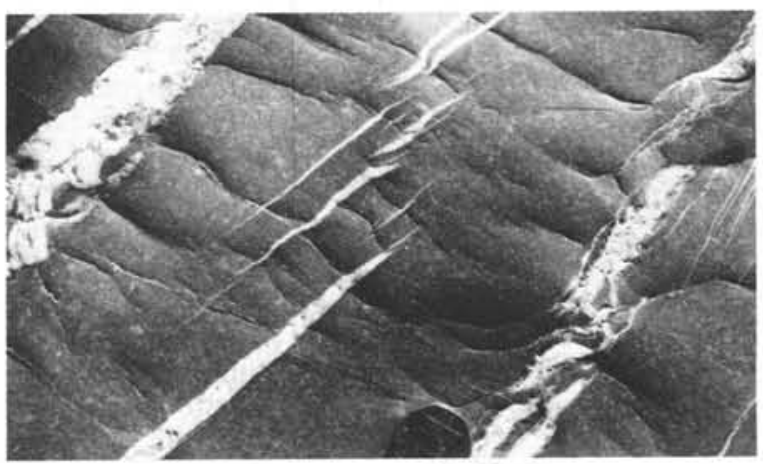

Figure 2: Pressure solution stripes and syntectonic veins developed as related structures in a deformed greywacke, North Devon. 


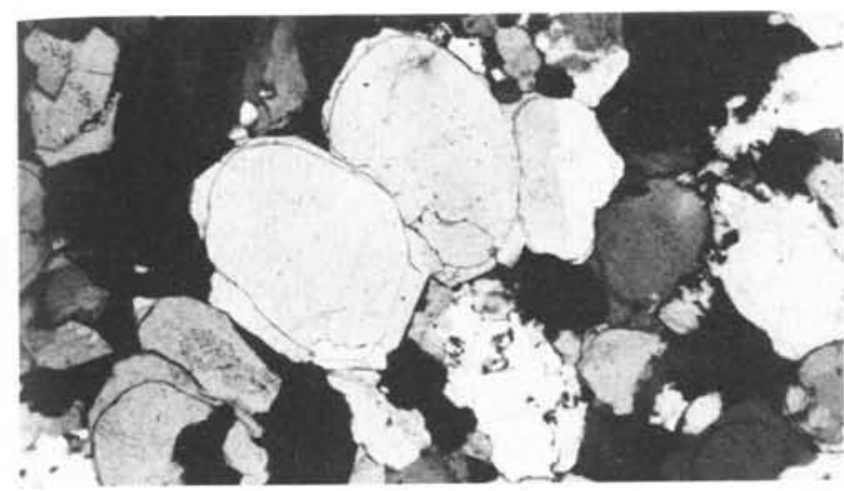

Figure 3: Congruent pressure solution of quartz grains. Detrital grain rims are preserved inside early diagenetic overgrowths, both of which are affected by pressure solution at grain contacts. Field width $2 \mathrm{~mm}$.

in the vicinity of the crack tip are broken by hydrolysis, and fracture propagation occurs at stress differences lower than those required for dry fracturing. Barnett and Kerrich (1980) have attempted to relate local changes in mineral chemistry to this process, which is known as stress corrosion cracking. However, it is not possible from their data to distinguish between localization of reactions ahead of fracture tips during stress corrosion cracking and alteration of minerals along fractures as a result of enhanced access of reactants.

\section{Stress Distribution Around Cracks And Stripes}

The model of an elliptical flaw in an infinite elastic medium is often used to evaluate geological fracture problems through calculation of the stress distribution around the crack under biaxial applied stress, with or without an internal fluid pressure. The role of hydraulic fracturing and subcritical crack growth are being increasingly advocated as two modes of formation of many naturally formed fractures (Beach, 1977; Anderson and Grew, 1977).

At crack tips, stress concentrations many times the regional value exist, and may be important for several reasons. First, water molecules attach themselves to stretched $\mathrm{Si}-\mathrm{O}$ bonds in the crack tip, and bond rupture ensues (stress corrosion sensu stricto). Second, gradients in chemical potential of the solid phase in equilibrium with the fluid phase exist, and enhanced diffusion of any component may occur. Third, ion exchange between crack fluid and crack wall may occur preferentially at crack tips in the area of lower mean stress where tensile stresses are concentrated. For stress corrosion in the strict sense, the log crack velocity is proportional to the log stress intensity, and crack tip reaction rate is the controlling factor in fracture growth (Anderson and Grew, 1977).

The geologically formed hydraulic fracture is the best possible environment for promoting subcritical crack growth since

- fractures are open and fluid filled, enabling free diffusion of components to and from reaction sites;

- elevated temperatures increase reaction rates;

- fluid filled cracks undergo stress corrosion at lower stress intensities than cracks with small concentrations of water vapour (Michalske and Freiman, 1982); and,

- the fluid is not pure water, but a brine with varying concentrations of cations and anions (plus $\mathrm{CO}_{2}$ ), promoting hydrothermal-type reactions (Helgeson, 1969) at the crack tip.

Unlike many metamorphic problems where diffusion is considered the rate-controlling step, subcritical growth of natural hydraulic fractures is likely to be reaction rate controlled (Michalske and Freiman, 1982). Thus, although there may be no record in the rock of a reaction related to crack growth (but see Barnett and Kerrich, 1980), it should be possible to constrain the types of reactions that may occur under certain conditions of temperature and fluid composition.

The converse problem to fracture stresses, that is the stress perturbation around a pressure solution stripe, has only recently been tackled by Fletcher and Pollard (1981) with what they term the anticrack model. Compressive stress concentrations exist at stripe tips and the mode of propagation is considered to be analogous to that for tensile cracks, i.e. stripes propagate along the surface to which the maximum compressive stress is normal.

The mechanism of stripe propagation may also be reaction rate controlled and may involve any process that responds to local variations in stress, such as preferential solution of minerals, ion exchange through the fluid, or mineral reactions. It is thus the opposite end of the sequence to the processes that may occur at crack tips.

\section{Role of the Fluid Phase}

A number of recent workers have developed a thermodynamic theory for deformation by pressure solution (e.g. Rutter, 1976) by evaluating the variations in chemical potential of a solid phase in equilibruim with a fluid phase when a rock is subjected to a differential stress. These treatments are simplified by restricting the concept of pressure solution to the dissolution of quartz and calcite, without identifying either solution mechanisms or coupled diffusion processes. These latter two aspects will now be briefly discussed.

Pressure solution commonly involves more complex minerals than quartz and calcite, not only in the formation of cleavage stripes, but also in the growth of pressure shadows. It is necessary to identify both the chernical mechanism of solution of minerals such as carbonates, white mica, chlorite and feldspars, and the process of diffusion of aqueous components of these minerals.

According to Helgeson (1969), quartz dissolves in water to form the neutral molecule $\mathrm{H}_{4} \mathrm{SiO}_{4}$. This may dissociate by simple ionization when the $\mathrm{pH}$ of the fluid phase is greater than 9 , and the overall concentration of silica in solution may be increased. Low concentrations of $\mathrm{H}^{+}$created in the fluid phase by local equilibrium with mineral reactions in a deforming rock may locally increase the solubility of quartz and hence increase the magnitude of the chemical potential gradients for silica away from reaction sites. Similarly, a local increase in equilibrium value of the concentration of $\mathrm{Na}^{+}$in the fluid phase in conjunction with a mineral reaction may increase the local concentration of silica in solution through the formation of soluble sodium silicate complexes. Such processes can of ten be anticipated from a consideration of the equilibrium between a mineral assemblage and the fluid composition (the latter recorded for example by fluid inclusions), together with the likely reaction paths during pressure solution.

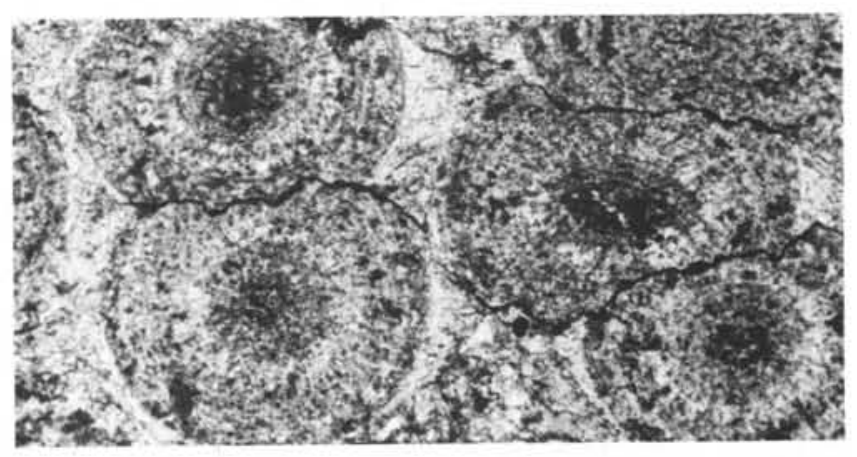

Figure 4: Congruent pressure solution of calcite ooliths. The fibrous calcite overgrowths are little affected by the stylolitic solution surfaces separating the grains. Field width 2 $\mathrm{mm}$. 


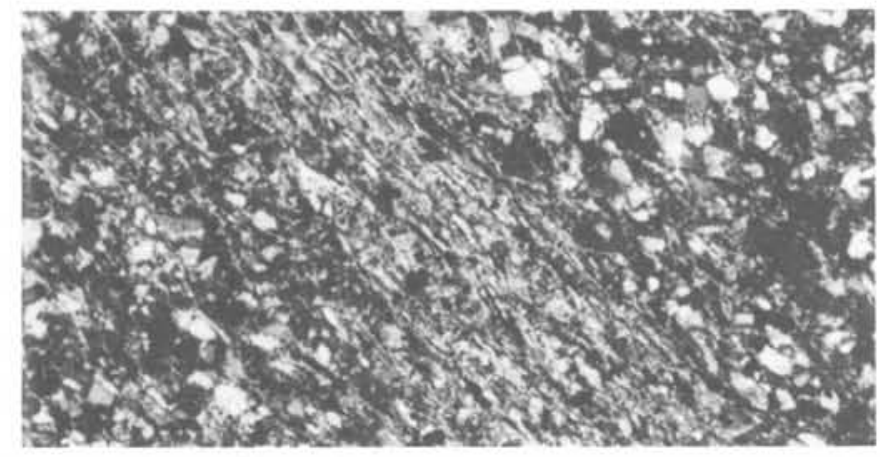

Figure 5: Pressure solution cleavage stripe in greywacke. Field width $2 \mathrm{~mm}$.

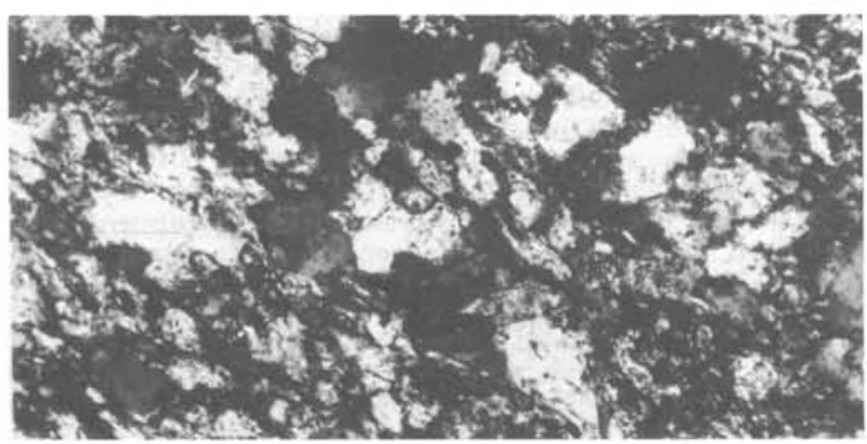

Figure 6: Detail of texture adjacent to pressure solution stripe shown in Figure 5. Irregular quartz and feldspar grains, detrital micas and diagenetic clays are present. Field width $0.1 \mathrm{~mm}$.

Calcite dissolves in water by ionic dissociation. Local solution, deposition and chemical potential gradients will depend on the $\mathrm{pH}$ and composition of the grain boundary fluid. The presence of ions in solution calls attention to two further problems. First, it is known that ions are surrounded by electrostatically coordinated water molecules, and the number of these, and hence the effective size of the solvated ion, will affect the rate of ion diffusion through the grain boundary fluid during pressure solution. Cations are generally more solvated than anions. Second, there is a tendency for different ions to diffuse at different rates, determined by their size and charge. In order to maintain electrical neutrality it may be necessary for two ions, for example of calcium and carbonate, to diffuse at the rate determined by the more slowly diffusing ion. However, cooperative or coupled diffusion may be set up whereby each ion has its own diffusion path and rate in a complex reaction scheme where the overriding condition is that overall electrical neutrality is maintained. Complex schemes with diffusion rates enhanced by cross-coupling may thus arise.

Pressure solution of feldspars, micas, chlorites and other minerals involves solution of both ions and molecules, fluid equilibria between these complexes, and in many cases precipitation in proportions different to those produced by solution. Such minerals are commonly involved in the processes leading to the formation of slaty cleavage and spaced cleavage stripes, and therefore deserve more attention than has hither to been devoted to them in this field.

Many of the pressure solution reactions referred to are well documented in hydrothermal studies (Helgeson, 1969) and sufficient data exist to evaluate equilibria up to $300^{\circ} \mathrm{C}$. Solution and precipitation mechanisms involve ions such as $\mathrm{H}^{+}, \mathrm{Na}^{+}, \mathrm{K}^{+}$, and $\mathrm{Ca}^{2+}$, and thus pressure solution depends on a complex solid-fluid equilibrium, susceptible to changes in $\mathrm{P}$, $\mathrm{T}, \mathrm{P}_{\mathrm{H}_{2} \mathrm{O}}$ and ionic concentrations.

\section{Pressure Solution Mechanisms}

A distinction can be made between congruent and incongruent pressure solution (cf. Beach, 1982). The former, which has been the subject of much theoretical and descriptive work, involves the dissolution and precipitation of the same phase or phases (Figure 3). For example quartz grains dissolve, so quartz overgrowths form. In contrast, incongruent pressure solution, which leads to the formation of many cleavage stripes, involves the dissolution of one or more phases such as feldspar and the precipitation of one or more different phases such as mica and quartz (Figure 8). A third category arises as an extension of congruent pressure solution where the mineral concerned shows solid solution changes in composition, for example from dissolved calcite to precipitated ferroan-calcite overgrowths.

An important question arises at this point. Are the phase and chemical changes observed merely a result of deformation? Are they carried passively by this process, or do they provide the prime driving force for pressure solution? In the former case, observation of these changes is merely a record that pressure solution has occurred, while in the latter it is important to understand the reaction mechanism in order to evaluate the rate of deformation by incongruent pressure solution.

In the majority of cases, phase changes provide part of the driving force for deformation by pressure solution. Both congruent and incongruent processes may be represented by chemical reactions, the former albeit trivial, with a diffusion step from source to sink. The rate of a chemical process is exponentially proportional to the reciprocal of the energy barrier that has to be overcome, and so can lower this energy barrier.

Textures in deformed rocks may indicate that the deformation mechanism maps produced by Rutter (1976) and others provide lower limits only for rates of pressure solution. For example, it has long been known that clay seams promote or "activate" pressure solution in sandstones (e.g. Heald, 1955), and a similar process may occur in spaced cleavage stripes. Quartz grains in direct contact with another quartz grain may show little pressure solution, whereas other grains in contact with clay or mica show strongly pressure-solved contacts. With the diffusion step rate controlling, the activation energy for diffusion is interpreted to be lowered along mica and clay contacts, and a diffusion mechanism for this has been proposed by Beach (1982), analogous to that invoked by Michalske and Freiman (1982) for the problem of subcritical crack growth by stress corrosion.

Calcite shows solid solution variation in composition, and under hydrostatic stress the chemical potential of the $\mathrm{CaCO}_{3}$ component in equilibrium with an aqueous solution will de-

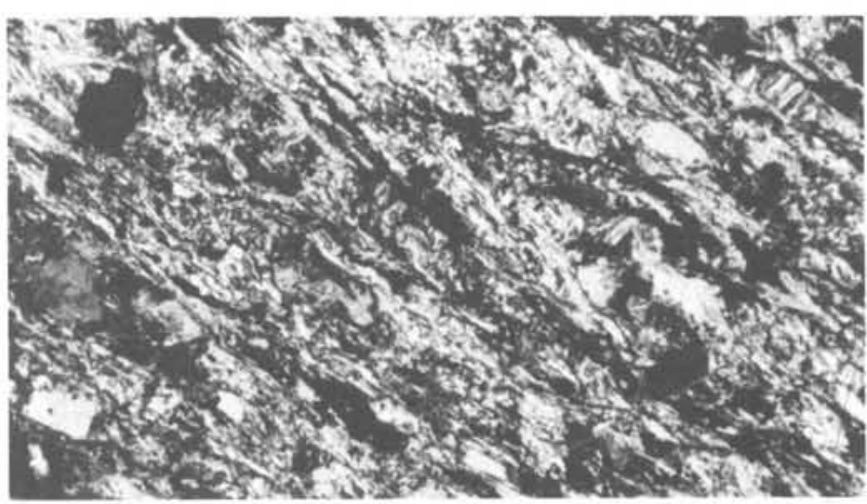

Figure 7: Detail of texture within pressure solution stripe shown in Figure 5. The increase in amount and the strong orientation of phyllosilicates compared with Figure 6 is evident. Field width $0.1 \mathrm{~mm}$. 
pend on the composition of the solid solution. In deformed rocks, solid solution is seen to occur under non-hydrostatic stress with ferroan-calcite over-growths on calcite grains (Beach 1982). In these rocks pure calcite was in local equilibrium with the grain boundary fluid at points of high stress where solution occurred, and at points of low stress where precipitation took place ferroan-calcite was in local equilibrium with the fluid. For the same differential stress, chemical potential gradients will be larger in the system where compositional variations occur than where pure calcite is both dissolved and precipitated, because of the chemical potential change related to the compositional difference. Conversely, pressure solution may proceed at lower values of differential stress where a compositional change can occur.

In the development of spaced cleavage stripes, both reduction in the activation energy for diffusion (through grain boundary effects) and enhancement of chemical potential gradients (through compositional changes and chemical reactions) are thought to have occurred. In general therefore, pressure

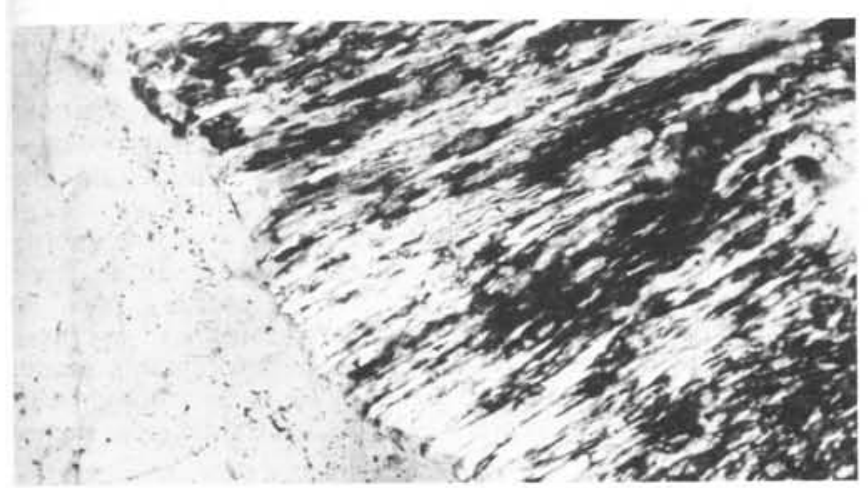

Figure 8: Incongruent pressure solution. Overgrowths of white mica and quartz on a detrital quartz grain, as a result of pressure solution breakdown of feldspar in a deformed greywacke. Field width $0.1 \mathrm{~mm}$.

solution structures may develop at lower differential stresses than those required by Rutter's (1976) analysis. An example is provided by the solution of detrital feldspars and the precipitation of phengite/muscovite-quartz overgrowths, either pervasively through a rock or in spaced stripes (Beach and King, 1978; Stephens et al., 1979; Beach, 1982).

\section{Conclusion}

Pressure solution structures need to be examined geometrically, mineralogically, and chemically. An increasing amount of quantitative data on fine-grained minerals will be required from the electron microscope, so that chemical reactions occurring during pressure solution may be formulated. Hydrothermal solution chemistry will aid the definition of realistic diffusion and reaction mechanisms.

A constraint on pressure solution may be imposed by examining the overall material balance. There are many examples of the synchronous development of pressure solution stripes and veins and Beach (1974) attempted to quantify the balance of $\mathrm{Si}, \mathrm{Ca}$ and $\mathrm{Fe}$ in such a system. Fletcher and Pollard (1981) develop the notion that the propagation of the fractures and the stripes are mutally dependent, forming closed cells where the crack volume and the anticrack (i.e. stripe) "antivolume" are equal.

In terms of the chemical ideas put forward, the propagation of cracks and stripes is controlled by the rates of chemical reactions at their tips (and one may be evaluated from the other), whilst the rate of bulk strain (shortening across seams and extension across veins) is controlled by the diffusion mechanism related to the chemical reactions. In studying rocks deformed by pressure solution, an attempt should therefore be made to determine the overall material balance, in order to understand the scale on which the chemical processes involved in pressure solution were operating.

\section{References}

Anderson, O.L. and Grew, P.C., 1977. Stress corrosion theory of crack propagation with applications to geophysics. Rev. Geophys. Space Phys., v. 15, p. 77-104.

Barnett, R.L. and Kerrich, R., 1980. Stress corrosion cracking of biotite and feldspar. Nature, London, v. 283, p. 185-187.

Beach, A., 1974. A geochemical investigation of pressure solution and the formation of veins in a deformed greywacke. Contrib. Mineral. Petrol., v. 46, p. 61-68.

Beach, A., 1977. Vein arrays, hydraulic fractures and pressure solution structures in a deformed flysch sequence, SW England. Tectonophysics, v. 40, p. 201-225.

Beach, A., 1979. Pressure solution as a metamorphic process in deformed terrigenous sedimentary rocks. Lithos, v. 12, p. 51-58.

Beach, A., 1982. Deformation mechanisms in some cover thrust sheets from the external French Alps. J. Structural Geol., v. 4, p. 137-149.

Beach, A. and King, M., 1978. Discussion on pressure solution. J. Geol. Soc. London, v. 135, p. 649-651.

Fletcher, R.C., and Pollard, D.D., 1981. Anticrack model for pressure solution surfaces. Geology, v. 9, p. 419-424.

Heald, M.T., 1955. Stylolites in sandstones. J. Geol. v. 63, p. 16-30.

Helgeson, H.C., 1969. Thermodynamics of hydrothermal systems at elevated temperatures and pressures. Am. J. Sci., v. 267, p. 729-804.

Knipe, R.J., 1982. Cleavage lamella border structures and microchemistry. In: Atlas of Deformational and Metamorphic Rock Fābrics, Borradaile, G.J. et al. (eds.), Springer-Verlag, Berlin, p. 146-7.

McClay, K.R., 1977. Pressure solution and Coble creep in rocks and minerals: a review. J. Geol. Soc. London, v. 134 , p. $57-70$.

Michalske, T.A. and Freiman, S.W., 1982. A molecular interpretation of stress corrosion in silica. Nature, London, v. 295, no. 5849, p. 511-2.

Rutter, E.H., 1976. The kinetics of rock deformation by pressure solution. R. Soc. Lond., Philos. Trans., v. A283, p. 203-219.

Stephens, M.B., Glasson, M.J. and Keays, R.R., 1979. Structural and chemical aspects of metamorphic layering development in metasediments from Clunes, Australia. Am. J. Sci., v. 279, p. 129-160.

\section{ABOUT THE AUTHOR:}

Alastair Beach graduated from Oxford University in 1968, and studied structural geology under John Ramsay at Imperial College, completing a Ph.D. there on deformation and metamorphism in shear zones in the Lewisian complex. Following ten years of lecturing at Liverpool University, he has recently joined the exploration team at the British National Oil Corporation (now Britoil), 150 St. Vincent Street, Glasgow, G2 5LJ, U.K.

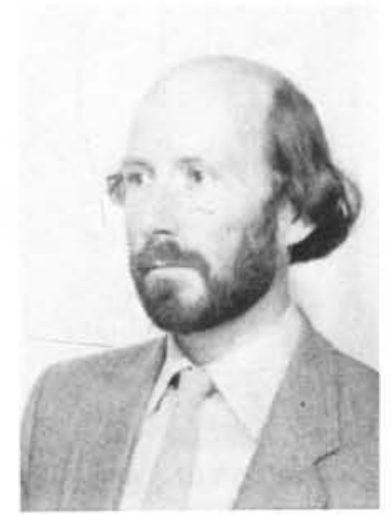

